\title{
Regardless of the Puncture Angle, a Tuohy Needle with Sand-Blasted Steel at the Tip of the Bevel Is a Valid Needle on the Ultrasonic Images
}

\author{
Yuki Ichikawa1, Hironobu Ueshima ${ }^{2 *}$, Hiroshi Otake², Akira Kitamura1 \\ ${ }^{1}$ Department of Anesthesiology, Saitama International Medical Center, Saitama, Japan \\ ${ }^{2}$ Department of Anesthesiology, Showa University Hospital, Tokyo, Japan \\ Email: ueshimhi@yahoo.co.jp
}

Received 29 June 2016; accepted 18 July 2016; published 21 July 2016

Copyright @ 2016 by authors and Scientific Research Publishing Inc.

This work is licensed under the Creative Commons Attribution International License (CC BY). http://creativecommons.org/licenses/by/4.0/

(c) (i)

\section{Abstract}

Background: A high ability to visualize the needle on the ultrasonic images is necessary to perform the ultrasound-guided nerve block safely. The Rafa Tuohy needle ${ }^{\mathrm{R}}$ (Vygon, Paris, France, Rafa) is a non-stimulating Tuohy needle with sand-blasted steel at the tip of the bevel. We examined the degree to which the Rafa enhanced the visibility of ultrasonic images compared with the non-coated Tuohy needle. Methods: We punctured the Blue Phantom. The dimensions of both the Rafa and the non-coated Tuohy needles were $18 \mathrm{G} \times 80 \mathrm{~mm}$. The puncture angle is 30 degrees and 45 degrees from the Blue Phantom. We measured the intensity of the tip of the bevel at a depth of 0.5, 1.0, 1.5 and $2.0 \mathrm{~cm}$ for the puncture angle of 30 degrees, and $0.5,1.0,1.5,2.0,2.5$ and $3.0 \mathrm{~cm}$ for the puncture angle of 45 degrees. Six anesthesiologists with more than seven years of experience performed three punctures using each needle. Results: As an outcome, we concluded that at a puncture angle of both 30 degrees and 45 degrees, the intensity of the non-coated Tuohy needle decreased with the depth. On the other hand, at an angle of 30 degrees, the intensity of the Rafa needle did not decrease, and at an angle of 45 degrees the intensity only decreased very slightly as the depth increased. Conclusions: The Tuohy needle with sand-blasted steel at the tip of the bevel provided greater visualization than the non-coated Tuohy needle on the ultrasound images.

\section{Keywords}

Puncture Angle, Sand-Blasted Steel, Ultrasonic Images

\footnotetext{
${ }^{*}$ Corresponding author.
} 


\section{Introduction}

When we perform the ultrasound-guided nerve blocks, we will encounter complications such as nerve or organ injuries, and local anesthetic systemic toxicity [1]-[3]. One of the reasons, which can cause some complications, is the poor visualization on the ultrasound images in performing the ultrasound-guided nerve blocks. Therefore, the needle has been devised in various ways in order to improve the visualization of the needle on the ultrasound images [4]-[7]. The Rafa Tuohy needle ${ }^{\mathrm{R}}$ (Vygon, Paris, France, Rafa) is a non-stimulating Tuohy needle with sand-blasted steel at the tip of the bevel. We can predict that the modification would also enhance the visibility of ultrasonic images regardless of some puncture angles. In this study, we examined the degree to which the Rafa enhanced the visibility of ultrasonic images compared with the non-coated Tuohy needle.

\section{Materials \& Methods}

We did not submit this study to an institutional review board due to lack of human testing with the Blue Phantom. We prepared the S-Nerve ultrasound system (SonoSite FUJIFILM, Washington, America) and the Blue Phantom for the peripheral nerve blocks (CAE Healthcare, Sarasota, FL). We punctured the Blue Phantom by using a 50-x high-frequency linear probe with a needle guide kit (Civco Medical Instrument Co., Orange City, IA). The dimensions of both the Rafa and the non-coated Tuohy needles were $18 \mathrm{G} \times 80 \mathrm{~mm}$. The puncture angle was 30 degrees and 45 degrees to the skin. We used Image $\mathrm{J}$ software, which is an image-processing program designed for scientific multidimensional images, to measure the intensity of the tip of the bevel at a depth of $0.5,1.0,1.5$ and $2.0 \mathrm{~cm}$ for the puncture angle of 30degrees, and 0.5, 1.0, 1.5, 2.0, 2.5 and $3.0 \mathrm{~cm}$ for the puncture angle of 45 degrees. Six anesthesiologists with more than seven years of experience performed the ultrasound-guided nerve block and made three punctures using each needle.

\section{Statistics}

The Student's t-test was used for statistical analysis, and significance was accepted at $\mathrm{p}<0.05$. The numerical variables of the intensity at the tip of the needle are expressed as mean (standard deviation) $\left(\mathrm{cd} / \mathrm{m}^{2}\right)$.

\section{Results}

We showed the intensity of two Tuohy needles at each point in Table 1 and Table 2. Table 1 was the intensity of the puncture angle set at 30 degrees and the intensity of Rafa was 194.7 (6.6), 183.5 (5.5), 190.1 (11.3), 182.8

Table 1. The intensity of each needles for the puncture angle of 30 degrees $(n=18)$. Data are expressed as mean (standard deviation) $\left(\mathrm{cd} / \mathrm{m}^{2}\right)$. Rafa = Rafa Tuohy needle. Non-coated $=$ Non-coated Tuohy needle. On the all point, the intensity of the Rafa was clearly higher than the intensity of the non-coated needle $(\mathrm{P}<0.0001)$.

\begin{tabular}{ccccc}
\hline & \multicolumn{4}{c}{ The depth from Blue Phantom (cm) } \\
\cline { 2 - 4 } & 0.5 & 1.0 & 1.5 & 2.0 \\
\hline Rafa & $194.7(6.6)$ & $183.5(5.5)$ & $190.1(11.3)$ & $182.8(5.5)$ \\
Non-coated & $134.8(4.2)$ & $116.8(7.9)$ & $94.5(4.4)$ & $67.6(1.4)$
\end{tabular}

Table 2. The intensity of each needles for the puncture angle of $45^{\circ}(\mathrm{n}=18)$. Data are expressed as mean (standard deviation) $\left(\mathrm{cd} / \mathrm{m}^{2}\right)$. On the all point, the intensity of the Rafa was clearly higher than the intensity of the non-coated needle $(\mathrm{P}<0.0001)$. Rafa $=$ Rafa Touhy needle. Non-coated $=$ Non-coated Touhy needle.

\begin{tabular}{|c|c|c|c|c|c|c|}
\hline & \multicolumn{6}{|c|}{ The depth from Blue Phantom (cm) } \\
\hline & 0.5 & 1.0 & 1.5 & 2.0 & 2.5 & 3.0 \\
\hline Rafa & $\begin{array}{l}194.0 \\
(7.3)\end{array}$ & $\begin{array}{l}188.3 \\
(5.6)\end{array}$ & $\begin{array}{c}187.2 \\
(4.9)\end{array}$ & $\begin{array}{c}179.4 \\
(4.9)\end{array}$ & $\begin{array}{l}172.0 \\
(4.5)\end{array}$ & $\begin{array}{c}163.8 \\
(7.5)\end{array}$ \\
\hline Non-coated & $\begin{array}{c}134.4 \\
(2.7)\end{array}$ & $\begin{array}{c}111.6 \\
(7.3)\end{array}$ & $\begin{array}{c}104.5 \\
(5.8)\end{array}$ & $\begin{array}{l}86.1 \\
(7.2)\end{array}$ & $\begin{array}{l}72.2 \\
(3.9)\end{array}$ & $\begin{array}{l}56.6 \\
(4.6)\end{array}$ \\
\hline
\end{tabular}


(5.5), at each depth of $0.5,1.0,1.5$ and $2.0 \mathrm{~cm}$ respectively on the ultrasound images, whereas the intensity of the non-coated Tuohy needle was 134.8 (4.2), 116.8 (7.9), 94.5 (4.4), 67.6 (1.4) at each respective depth. Table 2 was the intensity of the puncture angle set at 45 degrees and the intensity of Rafa was 194.0 (7.3), 188.3 (5.6), 187.2 (4.9), 179.2 (4.9), 172.0 (4.5), 163.8 (7.5) at each depth of $0.5,1.0,1.5,2.0,2.5$ and $3.0 \mathrm{~cm}$ respectively on the ultrasound images, whereas the intensity of the non-coated Tuohy needle was 134.4 (2.7), 111.6 (7.3), 104.5 (5.8), 86.1 (7.2), 72.2 (3.9), 56.6 (4.6) at each respective depth.

In all the readings we took, the intensity of the Rafa was clearly higher than that of the non-coated needle $(\mathrm{P}<$ 0.0001 ).

In the test with the puncture angle set at 30 degrees, the intensity of the non-coated Tuohy needle decreased with the depth. On the other hand, the intensity of the Rafa did not decrease with the depth at all (Figure 1).

In the test with the puncture angle set at 45degrees, the intensity of the non-coated Tuohy needle decreased with the depth. On the other hand, the intensity of the Rafa decreased only slightly with the increase of depth (Figure 2).

\section{Discussions}

We could prove the high visualization of the Rafa based on the results gotten for all the points where we gathered

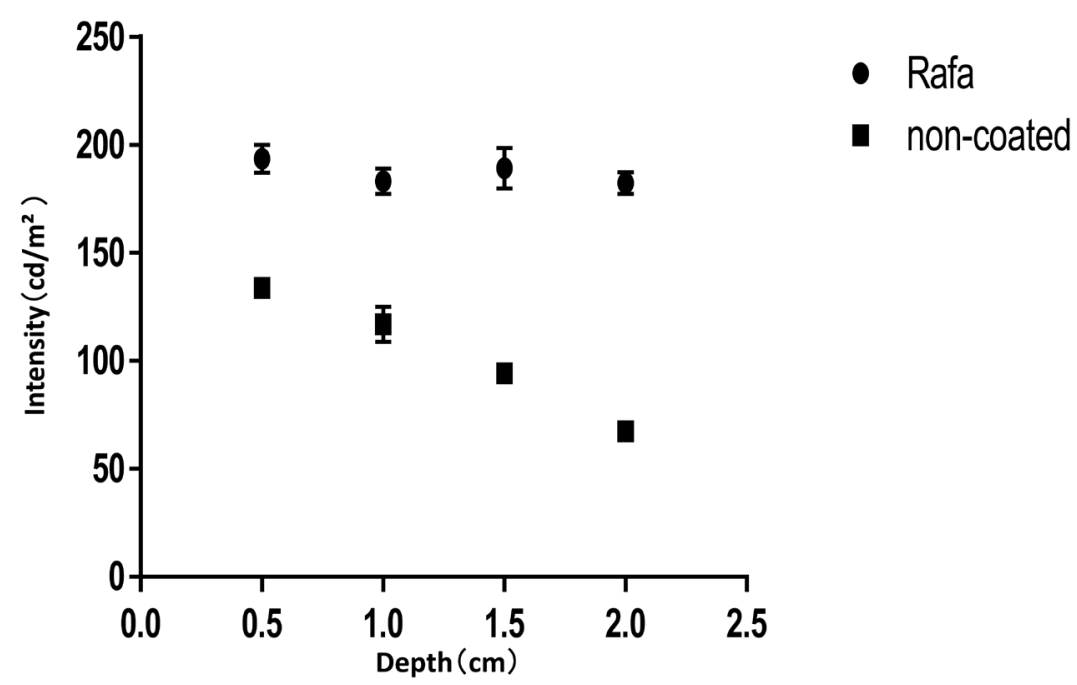

Figure 1. The intensity of each needle for the puncture angle of 30 degrees.

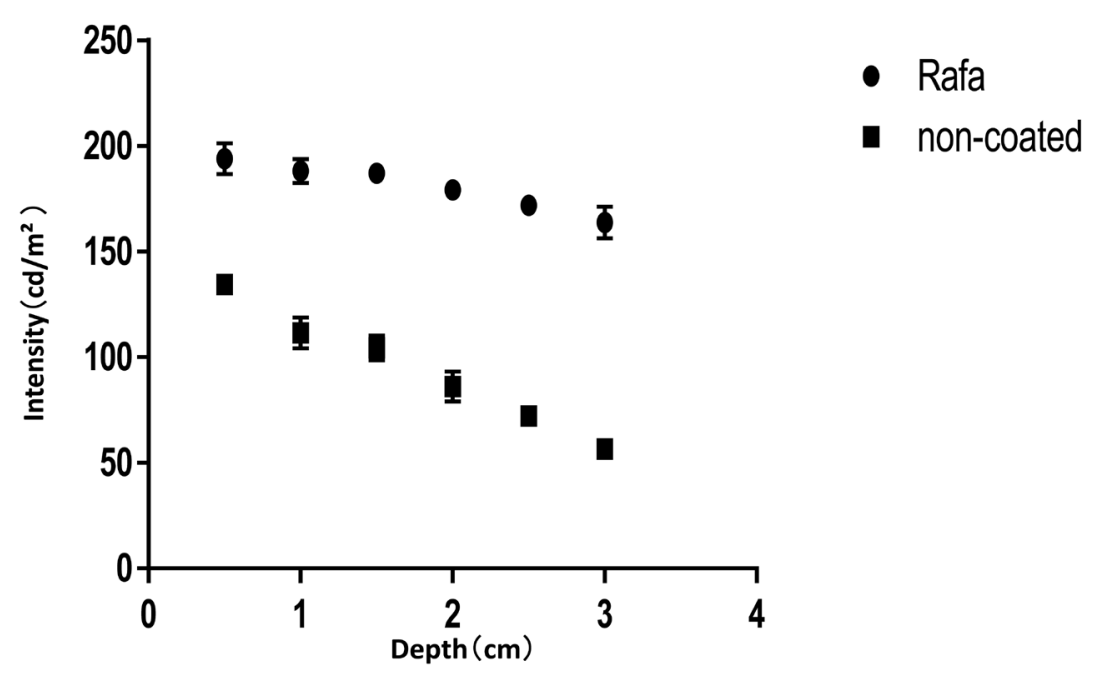

Figure 2. The intensity of each needle for the puncture angle of 45 degrees. 
data.

It has been generally reported that the larger the puncture angle is, the lower the visualization of the needle is [8] [9]. Therefore, the risk of the deep nerve block has arisen in comparison with the superficial nerve block [10]. This study also showed that the intensity of the non-coated Tuohy needle clearly decreased with the puncture angle and the depth. As the Rafa with sand-blasted steel at the tip of the bevel has shown validness on the ultrasound images regardless of the puncture angle and the depth, we are certain it will be effective for deep nerve blocks, such as the paravertebral nerve block and lumber plexus nerve block. It is also easy to check the tip position because only the tip is coated, not the entire needle.

The limitation of this study is caused by the lack of human study, due to the restrictions provided by the Blue Phantom, as it is not homogenous. Furthermore, we cannot measure the intensity at over $3 \mathrm{~cm}$ of depth because of the Blue Phantom. The puncture angles of this study are only 30 degrees and 45 degrees. In the future, we will need to perform this study in a clinical setting to confirm the clinical efficacy of this technique. As for the puncture angle, we will have to also perform the other puncture angles in next study.

In this study, the Rafa is a valid needle on the ultrasonic images. The Rafa will provide us the reliability and the safety to perform ultrasound-guided nerve blocks.

\section{Assistance with the Letter}

None.

\section{Financial Support and Sponsorship}

None.

\section{Conflict of Interest}

None.

\section{References}

[1] Vadi, M.G., Patel, N. and Stiegler, M.P. (2014) Local Anesthetic Systemic Toxicity after Combined Psoas Compartment-Sciatic Nerve Block: Analysis of Decision Factors and Diagnostic Delay. Anesthesiology, 120, 987-996. http://dx.doi.org/10.1097/ALN.0000000000000154

[2] Jacob, A.K., Mantilla, C.B., Sviggum, H.P., Schroeder, D.R., Pagnano, M.W. and Hebl, J.R. (2011) Perioperative Nerve Injury after Total Hip Arthroplasty: Regional Anesthesia Risk during a 20-Year Cohort Study. Anesthesiology, 115, 1172-1178. http://dx.doi.org/10.1097/aln.0b013e3182326c20

[3] Dhir, S., Ganapathy, S., Lindsay, P. and Athewal, G.S. (2007) Case Report: Ropivacaine Neurotoxicity at Clinical Doses in Interscalene Brachial Plexus Block. Canadian Journal of Anesthesia, 54, 912-916. http://dx.doi.org/10.1007/BF03026796

[4] Ueshima, H. and Otake, H. (2016) A Tuohy Needle with Engrave Processing at the Tip of the Bevel Is the Safety Needle for Ultrasound-Guided Nerve Block. Journal of Clinical Anesthesia, 32, 82-83. http://dx.doi.org/10.1016/j.jclinane.2015.12.029

[5] Ueshima, H., Nakagawa, M. and Otake, H. (2016) A Universal Echosupport Can Fix a Technique of UltrasoundGuided Continuous Femoral Nerve Block. Journal of Clinical Anesthesia, 31, 191-192. http://dx.doi.org/10.1016/j.jclinane.2016.01.046

[6] Ueshima, H. and Kitamura, A. (2015) A Needle with Sand-Blasted Steel at the Tip of the Bevel Is Valid for Ultrasound-Guided Deep Nerve Block. Journal of Clinical Anesthesia, 27, 363. http://dx.doi.org/10.1016/j.jclinane.2015.03.019

[7] Ueshima, H. and Kitamura, A. (2015) The Use of a Needle Guide Kit Improves the Stability of Ultrasound-Guided Techniques. Journal of Anesthesia, 29, 803-804. http://dx.doi.org/10.1007/s00540-015-2021-0

[8] Tsui, B.C.H. (2007) Facilitating Needle Alignment In-Plane to an Ultrasound Beam Using a Portable Laser Unit. Regional Anesthesia and Pain Medicine, 32, 84-88. http://dx.doi.org/10.1097/00115550-200701000-00015

[9] Schafhater-Zoppoth, I., McCulloch, C.E. and Gray, A.T. (2004) Ultrasound Visibility of Needle Used for Regional Nerve Block: And in Vitro Study. Regional Anesthesia and Pain Medicine, 29, 480-488.

[10] Klein, S.M., Faris, S., Celidonio, L., Tarantino, U., Fabbi, E. and Sabato, A.F. (2009) Retroperitoneal Haematoma in a Patient with Continuous Psoas Compartment Block and Enoxaparin Administration for Total Knee Replacement. British Journal of Anaesthesia, 103, 309-310. http://dx.doi.org/10.1093/bja/aep189 


\section{Submit or recommend next manuscript to SCIRP and we will provide best service for you:}

Accepting pre-submission inquiries through Email, Facebook, LinkedIn, Twitter, etc.

A wide selection of journals (inclusive of 9 subjects, more than 200 journals)

Providing 24-hour high-quality service

User-friendly online submission system

Fair and swift peer-review system

Efficient typesetting and proofreading procedure

Display of the result of downloads and visits, as well as the number of cited articles

Maximum dissemination of your research work

Submit your manuscript at: http://papersubmission.scirp.org/ 